To the Editors:

\title{
Re: Anaemia and iron deficiency in pregnant women attending an antenatal clinic in a Teaching Hospital in Southern Sri Lanka
}

S Mettananda ${ }^{1}$, DGH de Silva ${ }^{2}$

Ceylon Medical Journal 2017; 62: 255

DOI:http://doi.org/10.4038/cmj.v62i4.8582

We read with interest the article by Senadheera et al, which describe the rate of anaemia and iron deficiency in women presenting for antenatal care in a Teaching Hospital in the Galle District of Sri Lanka [1]. We agree with the content on the rate of anaemia defined as haemoglobin concentration $<11 \mathrm{~g} / \mathrm{dl}$ however, the subsequent analysis to determine a cut-off level of serum ferritin for detection of anaemia is inaccurate. Firstly, the use of serum ferritin as a screening tool for anaemia as proposed here is controversial. Although serum ferritin is a relatively accurate test to determine iron deficiency, it cannot be used to screen for anaemia. Secondly, it seems that authors have performed this study with an assumption that the aetiology for anaemia in the study population is exclusively iron deficiency but, given the high prevalence of haemoglobinopathies, in particular thalassaemia, in Sri Lanka, this assumption is not valid.

Thalassaemia is a long standing health problem which affects every ethnic group in all districts of Sri Lanka. The National prevalence of $\beta$-thalassaemia trait is reported as $2.8 \%$ and the prevalence in the Galle District where this study was conducted $1.0 \%$. Contrarily to previous believes, a recent island wide survey by Premawardhana et al. reported that the prevalence of $\alpha$-thalassaemia trait is as high as $8.0 \%$ in Sri Lanka and that it is found in every district including Galle [2]. As reviewed by us previously, $\alpha$-thalassaemia is commoner than $\beta$-thalassaemia and may in fact be as common as iron deficiency anaemia [3]. Therefore, it is highly likely that a major proportion of patients with anaemia in the study by Senadheera et al. have $\alpha$-thalassaemia trait or $\beta$-thalassaemia trait. Including the cohort of patients with $\alpha$-thalassaemia and $\beta$-thalassaemia trait would confound and possibly invalidate the analysis performed to determine the cut-off value of serum ferritin for detection of anaemia. More appropriate approach would be to exclude patients with haemoglobinopathies before analysing for cut-off level of serum ferritin.

\section{Conflicts of interest}

Authors decalre that they have no conflicts of interest.

\section{References}

1. Senadheera D, Goonewardene M, Mampitiya I. Anaemia and iron deficiency in pregnant women attending an antenatal clinic in a Teaching Hospital in Southern Sri Lanka. Ceylon Med J 2017;62(3): $175-83$

2. Premawardhena A, Allen A, Piel F et al. The evolutionary and clinical implications of the uneven distribution of the frequency of the inherited haemoglobin variants over short geographical distances. Br J Haematol 2017;176(3):475-84

3. Mettananda S, de Silva DG. Anaemia in children: are we using the correct prevention strategies? Ceylon Med J 2017;62(2):73-6

\footnotetext{
1Department of Paediatrics, Faculty of Medicine, University of Kelaniya, Sri Lanka, 2 Department of Paediatrics, Faculty of Medicine, University of Colombo, Sri Lanka (Former)

Correspondence: SM, e-mail: < sachithmetta@yahoo.com >. Received 30th October 2017 and accepted 16 November 2017.
}

This is an open-access article distributed under the terms of the Creative Commons Attribution License, which permits unrestricted use, distribution, and reproduction in any medium, provided the original author and source are credited. 